\title{
JURNAL
}

\section{Modifikasi Mesin Pencacah Plastik PET Tipe Gunting dengan Kapasitas 50 kg/jam}

\author{
Nuha Desi Anggraeni, Alfan Ekajati Latief, Alvin Rhamdani, Robby Rinaldi Sandi \\ Teknik Mesin Institut Teknologi Nasional Bandung, Indonesia \\ Jl. PKH. Mustapha No. 23, Bandung 40124 \\ e-mail : nuha@itenas.ac.id
}

\begin{abstract}
Abstrak
Mesin pencacah plastik merupakan sebuah mesin yang dirancang untuk mencacah sampah plastik agar mengurangi volume sampah. Mesin pencacah dirancang dapat mencacah sampah dengan kapasitas 50 kg/jam, hasil analisa kinerja mesin pencacah memperlihatkan bahwa kapasitas mesin pencacah adalah $36.68 \mathrm{~kg}$. Analisis kinerja mesin lain adalah: efisiensi mesin nilainya 73,37\%; tingkat kebisingan mencapai $80,6 \mathrm{~dB}$; getaran yang dihasilkan $4,9 \mathrm{~mm} / \mathrm{s}^{2}$, dan rendemen hasil pencacahan $73,45 \%$. Hasil analisa kinerja memperlihatkan bawah mesin pencacah perlu dimodifikasi agar sesuai dengan hasil perancangan awal. Modifikasi dilakukan dengan mengubah saringan, mengatur ulang jarak antara mata pisau, dan menambahkan pisau pada pisau putar. Modifikasi yang dilakukan berhasil meningkatkan kapasitas mesin pencacah menjadi 42,59 kg/jam; tingkat kebisingan menjadi 76,8 dB; tingkat getaran mesin 3,84 mm/ $\mathrm{s}^{2}$; dan kualitas hasil cacahan menjadi baik yaitu plastik terpotong.
\end{abstract}

Kata kunci: modifikasi, kinerja, sampah, daur ulang, mata pisau.

\section{Abstract}

Plastic chopper machine is a machine designed to chop plastic waste in order to reduce the volume of waste. The chopper is designed to be able to chop waste with a capacity of $50 \mathrm{~kg} / \mathrm{hour}$, the results of the performance analysis of the chopper show that the capacity of the chopper is $36.68 \mathrm{~kg}$. Analysis of the performance of other machines are: the efficiency of the machine is $73.37 \%$; noise level reaches $80.6 \mathrm{~dB}$; The vibration produced is $4.9 \mathrm{~mm} / \mathrm{s} 2$, and the yield of the census is $73.45 \%$. The results of the performance analysis show that the chopping machine needs to be modified to match the results of the initial design. Modifications were made by changing the filter, resetting the distance between the blades, and adding blades to the rotary blade. The modifications made succeeded in increasing the capacity of the chopping machine to $42.59 \mathrm{~kg} / \mathrm{hour}$; noise level to $76.8 \mathrm{~dB}$; engine vibration level $3.84 \mathrm{~mm} / \mathrm{s} 2$; and the quality of the chopped results is good, namely the plastic is cut.

Keywords: modification, performance, waste, recycling, blades. 


\section{Pendahuluan}

Tahun 2016, poduksi sampah di Indonesia mencapai 65,2 juta ton per tahun [1]. Sampah plastik merupakan penyumbang terbesar dalam produksi sampah. Sampah plastik yang jumlahnya banyak, ternyata dapat digunakan kembali untuk mengurangi produksi sampah. Pemanfaatan sampah plastik dapat dimulai dengan mengurangi volume sampah plastik. Pengurangan volume dilakukan dengan melakukan pencacahan plastik sehingga ukuran sampah plastik menjadi lebih kecil dan mudah untuk didaur ulang.

Mesin pencacah sampah yang telah direalisasikan, dirancang dapat mencacah sampah plastik, khususnya botol plastik tipe PET dengan kapasitas $50 \mathrm{~kg} / \mathrm{jam}$ [2]. Mesin pencacah dirancang menggunakan mesin diesel sebagai penggerak utama, konstruksi mesin dirancang agar mesin mudah dipindahkan, mekanisme pencacahan dipilih menggunakan tipe gunting untuk memudahkan pencacahan sampah plastik, digunakan lima buah mata pisau dengan dua mata pisau diam dan tiga mata pisau dinamis yang terhubung dengan poros [3]. Realisasi mesin pencacah diperlihatkan pada Gambar 1.

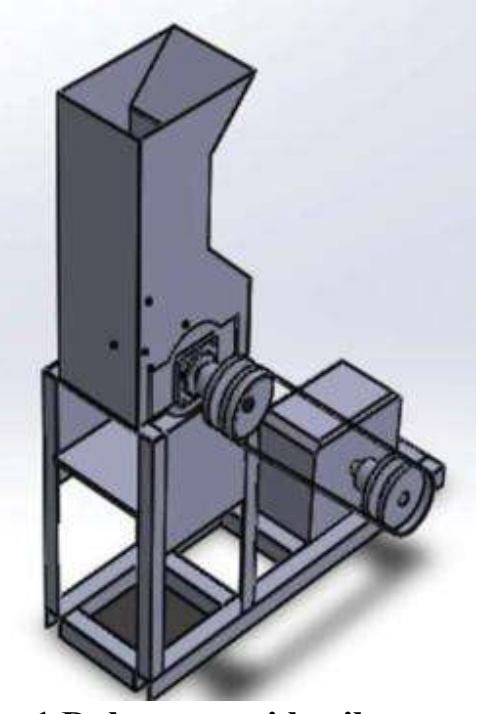

\section{Gambar 1 Dokumentasi hasil perancangan}

Spesifikasi teknis mesin pencacah plastik dengan kapasitas 50 kg/jam ditampilkan pada Tabel 1

Tabel 1 Spesifikasi Teknik Mesin Pencacah Plastik [2]

\begin{tabular}{|c|c|c|}
\hline \multirow[b]{3}{*}{ Poros } & Diameter & $30 \mathrm{~mm}$ \\
\hline & Panjang & $450 \mathrm{~mm}$ \\
\hline & Material & $\begin{array}{l}\text { S30C (Baja karbon konstruksi } \\
\text { mesin) } \\
\tau_{\text {yield }}=48 \mathrm{~kg} / \mathrm{mm}^{2}\end{array}$ \\
\hline \multirow{3}{*}{ Mata pisau } & Dimensi & $180 \mathrm{~mm} \times 50 \mathrm{~mm} \times 10 \mathrm{~mm}$ \\
\hline & Jumlah mata pisau & 5 buah ( 3 statik, 2 dinamik) \\
\hline & Material & $\begin{array}{l}\text { Baja perkakas JIS SKD } 11 \\
\tau_{\mathrm{y}}=589,38 \mathrm{Mpa}\end{array}$ \\
\hline \multirow{3}{*}{ Dudukan mata pisau } & Dimensi & $176 \mathrm{~mm} \times 50 \mathrm{~mm} \times 8 \mathrm{~mm}$ \\
\hline & Jumlah & 3 buah \\
\hline & Material & $\begin{array}{l}\text { Baja perkakas JIS SKD } 11 \\
\tau_{\mathrm{y}}=589,38 \mathrm{Mpa}\end{array}$ \\
\hline \multirow{4}{*}{ Iringan } & Diameter luar & $200 \mathrm{~mm}$ \\
\hline & Diameter dalam & $30 \mathrm{~mm}$ \\
\hline & Tebal & $10 \mathrm{~mm}$ \\
\hline & Jumlah piringan & 2 buah \\
\hline
\end{tabular}




\begin{tabular}{|l|l|l|}
\hline \multirow{5}{*}{ Pasak } & Material & $\begin{array}{l}\text { Baja perkakas JIS SKD 11 } \\
\tau_{\mathrm{y}}=589,38 \mathrm{Mpa}\end{array}$ \\
\hline \multirow{5}{*}{ Hopper } & Jenis pasak & Pin \\
\cline { 2 - 3 } & Panjang & $90 \mathrm{~mm}$ \\
\cline { 2 - 3 } & Diameter pin & $10 \mathrm{~mm}$ \\
\cline { 2 - 3 } & \multirow{4}{*}{ Material } & $\begin{array}{l}\text { Baut baja karbon rendah ASTM } \\
\text { A307 } \\
\left(\tau_{\mathrm{y}}=60 \mathrm{MPa}\right)\end{array}$ \\
\hline \multirow{5}{*}{ Konstruksi } & Panjang & $335 \mathrm{~mm}$ \\
\cline { 2 - 3 } & Lebar & $260 \mathrm{~mm}$ \\
\cline { 2 - 3 } & Tinggi & $650 \mathrm{~mm}$ \\
\hline \multirow{4}{*}{} & Tebal canal & $5 \mathrm{~mm}$ \\
\cline { 2 - 3 } & Panjang & $1000 \mathrm{~mm}$ \\
\cline { 2 - 3 } & Lebar & $340 \mathrm{~mm}$ \\
\cline { 2 - 3 } & Tinggi & $1500 \mathrm{~mm}$ \\
\hline & Daya & $3,3 \mathrm{~kW} / 4,5 \mathrm{HP}$ \\
\cline { 2 - 3 } & Daya rencana & $6,27 \mathrm{~kW}$ \\
\cline { 2 - 3 } & Daya motor diesel & $5 \mathrm{HP}$ \\
\hline
\end{tabular}

Mesin pencacah yang telah direalisasikan, kemudian diuji hasil kinerjanya, diperlihatkan pada Gambar 2. Analisa kinerja mesin sebelumnya memperlihatkan bahwa mesin pencacah plastik belum sesuai dengan rancangan awal. Hasil analisa kinerja adalah kapasitas aktual mesin pencacah adalah 36,68 kg/jam menghasilkan efisiensi mesin pencacah sebesar 73,37\%, nilai ini berada di atas standar minimal SNI yang ditetapkan yaitu 70\%. Rendemen pencacahan nilainya adalah $73,45 \%$ berada di bawah standar SNI yaitu $80 \%$. Nilai getaran mesin saat pencacahan adalah $4,9 \mathrm{~mm} / \mathrm{s}^{2}$, nilai ini berada di atas batas berbahaya standar ISO [4]. Tingkat kebisingan saat melakukan pencacahan adalah $80,6 \mathrm{~dB}$ berada di bawah standar tingkat kebisingan maksimum yang diperbolehkan yaitu $90 \mathrm{~dB}$ [5]. Hasil analisa kinerja meperlihatkan bahwa perlu dilakukan modifikasi agar kinerja mesin sesuai dengan hasil perancangan.

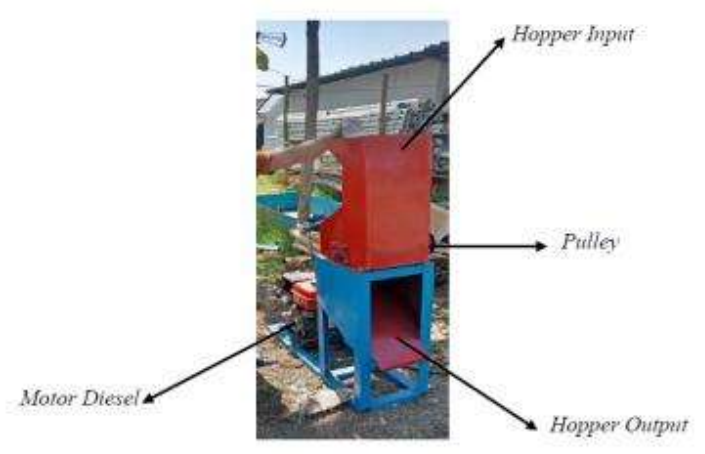

Gambar 2 Realisasi mesin pencacah plastik

\section{Metodologi}

Modifikasi mesin pencacah plastik diawali dengan mempelajari prinsip kerja mesin, menganalisa kinerja mesin pencacah dan masalah yang ditimbulkan, kemudian menentukan bagian-bagian mesin yang perlu dimodifikasi. Prinsip kerja mesin diuraikan menggunakan skema pada Gambar 3. Sampah plastik dicacah mata pisau yang digerakkan oleh motor diesel. Pulley digunakan untuk meneruskan daya motor diesel, kemudian menggerakkan poros penggerak yang terhubung dengan mata pisau. 


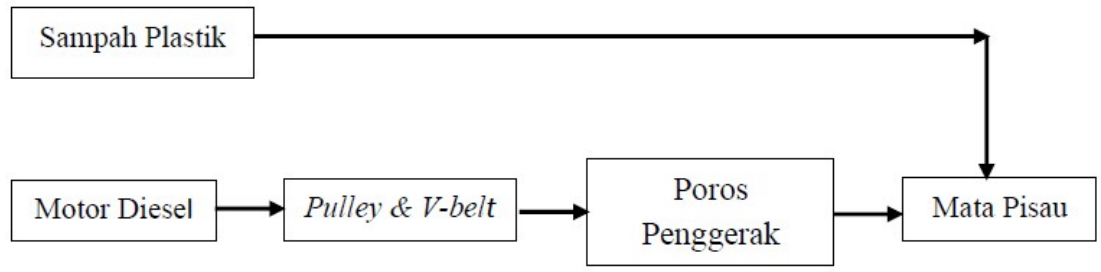

\section{Gambar 3 Prinsip kerja mesin pencacah plastic}

Analisis kinerja mesin pencacah plastik memperlihatkan masalah-masalah yang mengakibatkan mesin perlu dimodifikasi, masalah tersebut adalah:

a. Daya yang ditransmisikan motor diesel tidak stabil, akibat perbedaan ukuran dudukan mesin diesel dengan dimensi mesin yang digunakan.

b. Lubang filter cenderung menahan sampah plastik yang telah tercacah, diperlihatkan pada Gambar 4 [4]. Jarak antara lubang filter terlalu jauh sehingga plastik hasil cacahan tidak diteruskan ke corong keluaran (hopper output).

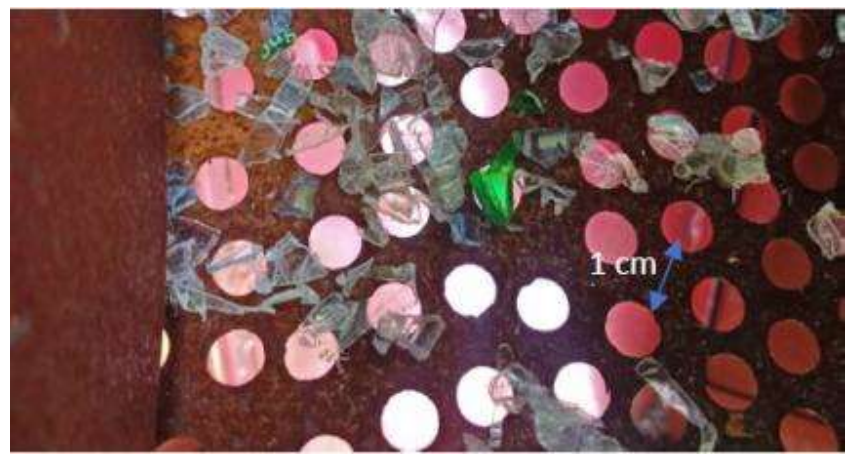

Gambar 4 Filter mesin pencacah plastic

c. Ruas antara mata pisau terlalu lebar, yaitu $120 \mathrm{~mm}$ (diperlihatkan pada Gambar 4), mengakibatkan cacahan plastik tersangkut di antara ruas pisau putar [4].

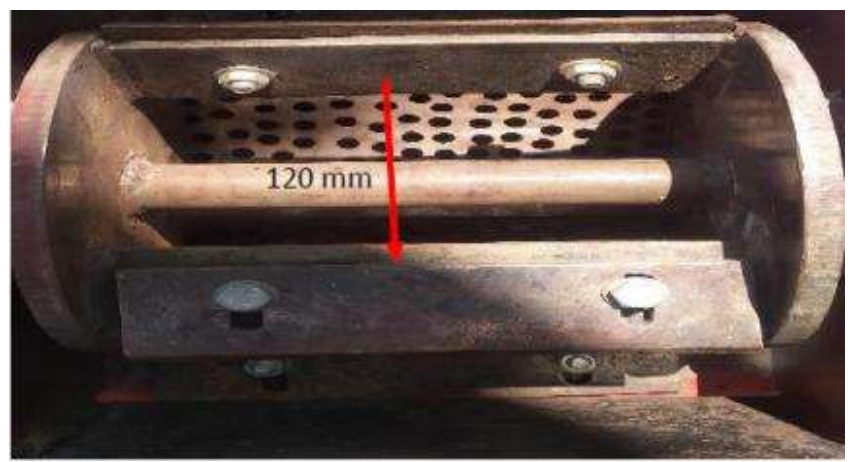

Gambar 5 Celah antara pisau

Melalui analisa masalah pada mesin pencacah, maka perlu dilakukan modifikasi pada bagianbagian berikut:

a. Memodifikasi dudukan mesin diesel dengan menambahkan dudukan pada rangka. Material yang digunakan adalah plat baja pada kedua bagian mesin diesel dengan dimensi $(5,5 \times 22 \times 5) \mathrm{cm}$.

b. Mengganti filter dengan memodifikasi ukurannya, yaitu mengubah jarak antara lubang menjadi $4 \mathrm{~mm}$.

c. Menambahkan tiga buah pisau putar untuk memperkecil ruas jarak antara pisau agar pisau dapat mencacah dengan baik. 


\section{Hasil dan Pembahasan}

Hasil modifikasi yang dilakukan diuraikan sebagai berikut:

a. Modifikasi dudukan mesin diesel.

Dimensi mesin diesel yang digunakan pada penelitian sebelumnya berbeda dengan dimensi dudukan, sehingga dudukan mesin diesel dimodifikasi [6]. Hasil modifikasi dudukan mesin diesel diperlihatkan pada Gambar 7. Modifikasi yang dilakukan adalah menambah ukuran lubang dudukan mesin diesel, dari $3 \mathrm{~cm}$ menjadi $6 \mathrm{~cm}$.

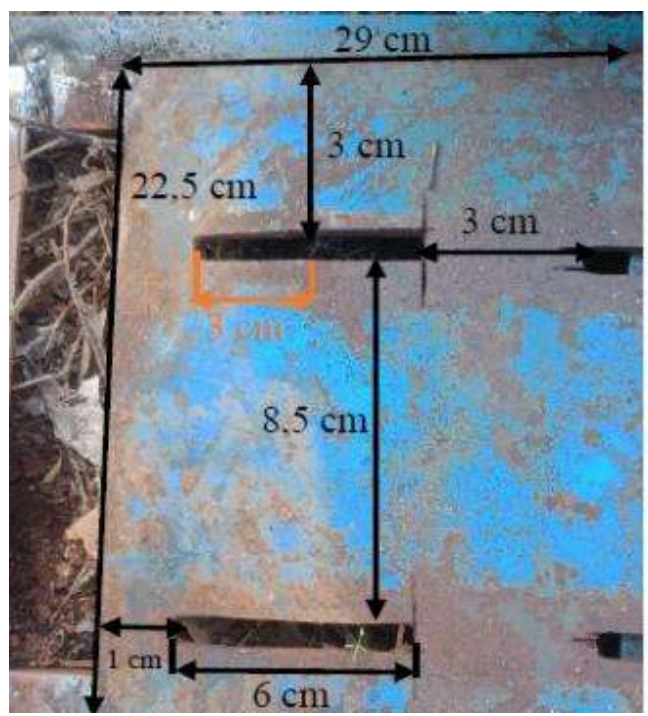

\section{Gambar 6 Dudukan mesin diesel sebelum modifikasi}

b. Jarak antar lubang pada filter awal memiliki ukuran $1 \mathrm{~cm}$ dengan diameter lubang $1 \mathrm{~cm}$ menyebabkan sering terjadinya cacahan plastik yang tersangkut. Untuk mengatasinya maka dilakukan modifikasi pada filter mesin pencacah dengan cara membuat filter baru dengan jarak antara lubang 0,4 cm dengan diameter tetap, sehingga akan lebih banyak biji plastik yang keluar dari lubang filter. Hasil modifikasi filter diperlihatkan pada Gambar 7.

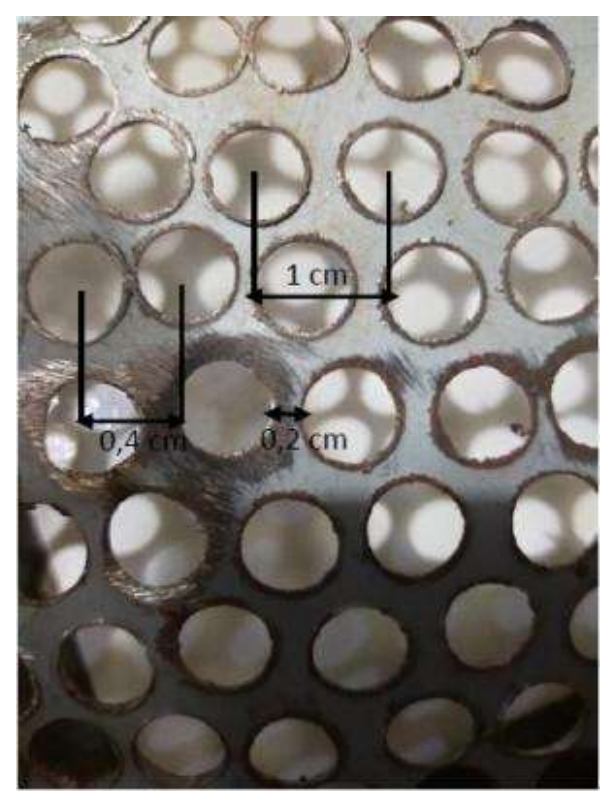

Gambar 7 Hasil modifikasi filter 
c. Pisau gerak memiliki 3 pisau pencacah dengan dimensi, diameter plate (piringan) 200 $\mathrm{mm}$, panjang $180 \mathrm{~mm}$, lebar $50 \mathrm{~mm}$ sedangkan jarak antara pisau yaitu $120 \mathrm{~mm}$, dengan kemiringan $35^{\circ}$ [7]. Jarak $120 \mathrm{~mm}$ antar pisau mengakibatkan botol plastik tersangkut di antara pisau, sehingga botol yang tersangkut tidak tercacah dengan sempurna bahkan tidak tercacah sama sekali. Masalah tersebut diatasi dengan menambahkan jumlah mata pisau pada pisau gerak yang berjumlah 6 pisau gerak, sehingga jarak antar mata pisau menjadi $50 \mathrm{~mm}$. Hasil modifikasi mata pisau diperlihatkan pada Gambar 8.

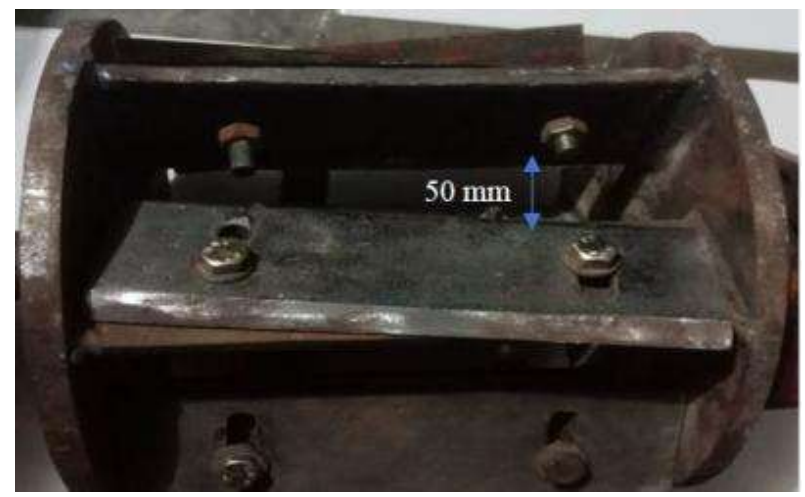

Gambar 8 Hasil modifikasi mata pisau

Kinerja mesin pencacah plastik hasil modifikasi dilakukan sesuai dengan analisa kinerja awal [4]. Hasil analisa kinerja mesin diperlihatkan pada hasil pengujian dalam Tabel 2.

Tabel 2 Kinerja mesin hasil modifikasi

\begin{tabular}{|l|c|c|}
\cline { 2 - 3 } \multicolumn{1}{c|}{} & Awal & Setelah modifikasi \\
\hline Kapasitas & $36,68 \mathrm{~kg} / \mathrm{jam}$ & $42,59 \mathrm{~kg} / \mathrm{jam}$ \\
\hline Efisiensi & $73,37 \%$ & $85 \%$ \\
\hline Rendemen pencacahan & $73,45 \%$ & $87,5 \%$ \\
\hline Tingkat getaran mesin & $4,9 \mathrm{~mm} / \mathrm{s}^{2}$ & $3,84 \mathrm{~mm} / \mathrm{s}^{2}$ \\
\hline Tingkat kebisingan & $80,6 \mathrm{~dB}$ & $76,8 \mathrm{~dB}$ \\
\hline
\end{tabular}

Kualitas hasil cacahan mesin diperlihatkan pada Gambar 9, dari gambar terlihat bahwa plastik terpotong dengan baik oleh pisau.

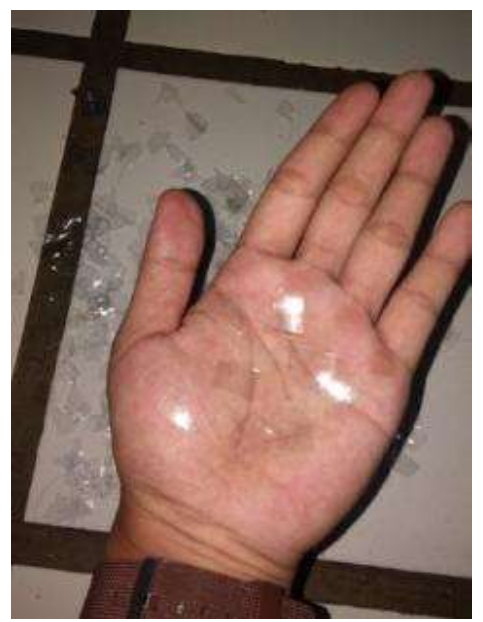

Gambar 9 Hasil cacahan mesin setelah dimodifikasi 


\section{Kesimpulan dan Saran}

Modifikasi pada mesin pencacah meningkatkan kinerja mesin. Kapasitas pencacahan awal besarnya 36,68 kg/jam mengalami peningkatan sebesar 5,94 kg/jam menjadi 42,59 kg/jam. Efisiensi mesin meningkat $11,63 \%$, efisiensi awal 73,37\% meningkat menjadi $85 \%$. Rendemen hasil pencacahan meningkat 14,05\%, hasil rendemen awal adalah 73,45 \% meningkat menjadi $87,5 \%$. Tingkat getaran mesin mengalami penurunan menjadi $3,84 \mathrm{~mm} / \mathrm{s}^{2}$, hasil ini menyatakan bahwa mesin masih dalam kondisi aman untuk digunakan. Tingkat kebisingan mengalam penurunan 3,8 dB, meskipun pada analisa kinerja awal masih di bawah kebisingan.

\section{Daftar Pustaka}

[1] Badan Pusat Statistik, "Statistik Lingkungan Hidup Indonesia (SLHI) 2018," Badan Pus. Stat. Indones., 2018, doi: 3305001.

[2] N. D. Anggraeni and A. E. Latief, "Rancang Bangun Mesin Pencacah Plastik Tipe Gunting," J. Rekayasa Hijau, 2018, doi: 10.26760/jrh.v2i2.2397.

[3] A. E. Latief, N. D. Anggraeni, and A. Sulaeman, "Perancangan Poros dan Mata Pisau Mesin Pencacah Plastik," in Seminar Nasional Tahunan Teknik Mesin XV (SNTTM XV), 2016, pp. 1095-1100.

[4] N. D. Anggraeni, A. E. Latief, and I. Dermawan, "Analisa Kinerja Mesin Pencacah Botol Plastik Tipe Pet," Mach. J. Tek. Mesin, vol. 5, no. 2, pp. 31-35, 2019, doi: 10.33019/jm.v5i2.1068.

[5] D. E. Izraul Machdar, Pengantar Pengendalian Pencemaran (pencemaran air, pencemaran udara, kebisingan). 2018.

[6] T. Rochim, Teori dan Teknologi Proses Pemesinan. 1998.

[7] R. Budynas and J. K. Nisbett, Shigley's Mechanical Engineering Design. 2015. 